\title{
Ion exchange resins as catalysts for the liquid-phase dehydration of 1-butanol to
} di-n-butyl ether

\author{
M.A. Pérez, R. Bringué, M. Iborra, J. Tejero*, F. Cunill \\ Department of Chemical Engineering, University of Barcelona, C/Martí i Franquès, 1, 08028 - \\ Barcelona \\ *Corresponding author: Phone: +34 93402 1308; fax: +34 93402 1291. E-mail address: \\ jtejero@ub.edu (J. Tejero)
}

\begin{abstract}
This work reports the production of di-n-butyl ether (DNBE) by means of 1-butanol dehydration in the liquid phase on acidic ion-exchange resins. Dehydration experiments were performed at $150{ }^{\circ} \mathrm{C}$ and 40 bar on 13 styrene-codivinylbenzene ion exchangers of different morphology. By comparing 1-butanol conversions to DNBE and initial reaction rates it is concluded that oversulfonated resins are the most active catalysts for 1-butanol dehydration reaction whereas gel-type resins that swell significantly in the reaction medium as well as the macroreticular thermostable resin Amberlyst-70 are the most selective to DNBE. The highest DNBE yield was achieved on Amberlyst 36. The influence of typical 1-butanol impurities on the dehydration reaction were also investigated showing that the presence of 2-methyl-1-propanol (isobutanol) enhance the formation of branched ethers such as 1-(1-methylpropoxy) butane and 1-(2methylpropoxy) butane, whereas the presence of ethanol and acetone gives place to ethyl butyl ether and, in much lesser extent, diethyl ether.
\end{abstract}

Keywords: Di-n-butyl ether (DNBE), ion-exchange resins, 1-butanol dehydration.

\section{Introduction}

Dependence on fossil fuels has raised two main concerns: on one hand, the associated environmental effects; on the other, oil reserves limitation and future depletion. Given the severity of these threats the European Union has ruled increasingly stringent specifications for: 
(1) quality of petrol, diesel and gas-oil (Directive 2009/30/EC); (2) emissions from light passenger and commercial vehicles (Regulation EC 715/2007); and (3) promotion of the use of energy from renewable sources, setting a mandatory $10 \%$ minimum target to be achieved by all Member States for the share of biofuels in transport petrol and diesel consumption by 2020 (Directive 2009/28/EC).

Although very efficient, diesel engines have had difficulties achieving desirable emission targets, especially for soot and $\mathrm{NO}_{\mathrm{x}}$ formation [1]. Reformulation of diesel fuel to include oxygenates has proven to be an effective way to provide satisfactory engine power and cleaner exhaust without modification of existing diesel engines [2-5].

A number of oxygenates have been considered as components for diesel fuel including various alcohols, ethers and esters. Alcohols have several drawbacks: high water solubility, which can cause phase separation problems; high Reid vapor pressure (RVP), which may lead to the plugging of the fuel flow by increasing the vapor pressure; high volatility, which increases the volatile organic compounds emissions; high latent heat of vaporization, which raises cold startup and drivability issues; and low heating value [6].Vegetable oil methyl esters have a number of properties non suitable for diesel fuels such as higher boiling point, viscosity, and surface tension that may contribute to increase the $\mathrm{NO}_{\mathrm{x}}$ emissions [7]. On the other hand, ethers show the best properties for diesel blends such as high cetane number, cold flow properties and mixture stability. In a comprehensive study on the blending properties of different oxygenates in diesel fuel, including monoethers, polyethers and esters, it was observed that linear monoethers with more than 9 carbon atoms showed the best balance among blending cetane number and cold flow properties which are measured by the Cloud Point (CP) and the Cold Filter Plugging Point (CFPP) [8]. Linear ethers have also shown to be effective in reducing diesel exhausts such as $\mathrm{CO}$, particulate matter and unburned hydrocarbons and to substantially improve the trade-off between particulate and $\mathrm{NO}_{\mathrm{x}}$ due to the presence of oxygen in the ether molecules [9].

It is quoted in the open literature that linear symmetrical ethers are produced by bimolecular dehydration of primary alcohols over acid catalysts [10],[11]. Nowadays the main synthesis 
route of primary alcohols is based on the oxo process. It consists of selective hydroformylation and hydrogenation of linear olefins from fluid catalytic cracking in the presence of $\mathrm{Rh}$ and $\mathrm{Co}$ phosphines [12]. In this way 1-butanol is mainly produced by the oxo synthesis process of propylene in which aldehydes from propylene hydroformylation are hydrogenated to yield 1butanol. With this hydrogenation step 1-butanol is obtained jointly with 2-methyl-1-propanol (isobutanol) as byproduct. Afterwards, the bimolecular dehydration reaction of the primary alcohol gives the corresponding ether. Although superior alcohols can also be produced from biomass by condensation of bioethanol and/or biomethanol (Guerbet Catalysis) [13], this is still a developing technology which is not yet commercialized [14]. However, biomass fermentation by microorganisms of the genus Clostridium giving place to 1-butanol along with acetone and ethanol (Acetone Butanol Ethanol or ABE fermentation) is being performed on the industrial scale [15], [16]. Thus, di-n-butyl ether can be considered a promising oxygenate to blend with diesel fuel as it keeps a good balance between cetane number and cold flow properties [17] and, in addition, it can be obtained from biomass and therefore, it could compute for the biofuel target.

Both an intermolecular dehydration (ether formation) and an intramolecular dehydration (olefin formation) may occur in the alcohol dehydration reaction. The prevailing pathway depends on the reaction conditions as well as the reactant and catalyst used. Solid acids such as zeolites [18], aluminum phosphates [19], amorphous aluminosilicates (AAS) [18], microporous niobium silicates [20], ฤ-alumina [17], and heteropolyacids [21],[22] have been tested as catalysts in the dehydration of 1-butanol. In the gas phase selectivity is highly dependent on conversion. Over $\mathrm{AlPO}_{4}$ the dehydration of 1-butanol gives place mainly to butenes at 1-butanol conversions $>75$ $\%$ (fixed-bed reactor, atmospheric pressure, $\mathrm{T}=300^{\circ} \mathrm{C}$ ), what suggests that the intramolecular dehydration of 1-butanol to 1-butene and the subsequent isomerization to trans-2-butene and cis-2-butene take place [19]. Butene was the major product for the dehydration reaction on AAS over the whole temperature tested (flow microreactor, $105-185^{\circ} \mathrm{C}, 1 \mathrm{~atm}$ ) [18]. At the same set-up and experimental conditions, selectivity to ether over H-ZSM-5 was higher than on AAS 
at about $2 \%$ alcohol conversion, but it decreased remarkably on increasing 1-butanol conversion [18]. In the dehydration of $\mathrm{C}_{5}-\mathrm{C}_{12}$ linear alcohols over $\eta$ - alumina (fixed bed reactor, $250-$ $350{ }^{\circ} \mathrm{C}, 0-4 \mathrm{MPa}$, WHSV $=1-4 \mathrm{~h}^{-1}$ ) it was observed that temperatures as high as $300^{\circ} \mathrm{C}$ were necessary to achieve over $60 \%$ conversion of 1-butanol; selectivity to ethers being lower than $30 \%$ [17]. Finally, 1-butanol dehydrated selectively to butenes over microporous niobium silicate as well $\left(150-300{ }^{\circ} \mathrm{C}, 1 \mathrm{~atm}\right)$ [20]. On the contrary, the liquid phase etherification of 1 butanol to di-n-butyl ether has been studied on heteropolyacids with different heteroatoms (200 ${ }^{\circ} \mathrm{C}, 30$ bars) showing that 1-butanol dehydrates selectively to di-n-butyl ether achieving over $80 \%$ ether selectivity with 1-butanol conversions ranging from 30 to $80 \%$ [22].

It is well-known fact that acidic ion-exchange resins are highly selective catalysts to produce linear symmetrical ethers from n-alcohols, avoiding byproducts as olefins [23-26]. However, to the best of our knowledge the synthesis of di-n-butyl ether does not have been reported on ionexchangers. Thus, the aim of the present paper is to study the liquid-phase dehydration of 1butanol to DNBE over t ion-exchange resins of different morphology and discuss the relationship between resins properties and their catalytic behavior. Influence of typical 1butanol impurities on 1-butanol dehydration reaction is also discussed.

\section{Experimental}

\subsection{Chemicals}

1-butanol ( $\geq 99.4 \%$ pure; $\leq 0.1 \%$ butyl ether; $\leq 0.1 \%$ water) and 2-methyl-1-propanol $(\geq$ $99.45 \%$ pure; $\leq 0.05 \%$ water $)$ supplied by Acros Organics, acetone $(\geq 99.8 \%$ pure; $\leq 0.2 \%$ water) supplied by Fisher Chemical and ethanol $(\geq 99.8 \%$ pure; $\leq 0.02 \%$ water; $\leq 0.02 \%$ methanol; $\leq 0.02 \% 2$-Butanol) supplied by Panreac were used as reactants.

DNBE ( $\geq 99.0 \%$ pure; $\leq 0.05 \%$ water) supplied by Acros Organics, 1-butene ( $\geq 99.0 \%$ pure) supplied by Sigma Aldrich, cis-2-butene ( $\geq 98.0 \%$ pure) supplied by TCI and water were used for analysis purposes.

\subsection{Catalysts}


Tested catalysts were acidic styrene-codivinylbenzene ion exchange resins: the monosulfonated macroreticular ones Amberlyst 15, Amberlyst 16 and Amberlyst 39 (high, medium and low crosslinking degree, respectively); the oversulfonated macroreticular resins (in which the concentration of $-\mathrm{HSO}_{3}$ groups has been increased beyond the usual limit of one group per benzene ring [27]) Amberlyst 35 (high crosslinking degree) and Amberlyst 36 (medium crosslinking degree) which are oversulfonated versions of Amberlyst 15 and Amberlyst 16 respectively; the chlorinated macroreticular resins Amberlyst 70 and CT-482; the macroreticular resin sulfonated exclusively at the polymer surface Amberlyst 46; and the monosulfonated geltype resins Dowex 50Wx8, Dowex 50Wx4, Amberlyst 31, Dowex 50Wx2 and Amberlyst 121 containing from 8 to $2 \mathrm{DVB} \%$. Short names and properties are given in Table 1.

118 It is well known that ion-exchange resins swell in polar media. As a result, morphology changes 119 and non-permanent pores appear. Table 2 shows the morphological parameters both in dry state and swollen in water of tested resins. As seen, macroreticular resins present BET surface areas ranging between $0.02-57.4 \mathrm{~m}^{2} / \mathrm{g}$ (pore volume between $0.0-0.328 \mathrm{~cm}^{3} / \mathrm{g}$ ). Nevertheless, the same resins show a surface area (and pore volume) increase up to $147-214 \mathrm{~m}^{2} / \mathrm{g}(0.333-1.05$ $\mathrm{cm}^{3} / \mathrm{g}$ ) when swelling in water making clear that new pores with lower pore diameter appear. A useful description of the nature and characteristics of these spaces can be obtained from Inverse Steric Exclusion Chromatography (ISEC) data. In macroreticular resins a part of these new open spaces in the range of mesopores can be characterized by the cylindrical pore model ("true pores"). However, this model is not applicable to describe spaces between polymer chains in the in the swollen polymer (micropores). A good view of the three-dimensional network of swollen polymer is given by the geometrical model developed by Ogston [29] in which micropores are described by spaces between randomly oriented rigid rods. The characteristic parameter of this model is the specific volume of the swollen polymer (volume of the free space plus that occupied by the skeleton), $\mathrm{V}_{\mathrm{sp}}$. The Ogston model also allows to distinguish zones of swollen gel phase of different density or polymer chain concentration (total rod length per volume unit 
134 of swollen polymer, $\mathrm{nm}^{-2}$ ). According to Ogston model, density of polymer chains is described 135 as the total rod length per unit of volume. Figure 1 shows the distribution of different polymer 136 density zones of swollen catalysts in aqueous phase. As seen, gel-type resins Amberlyst 121, 137 Dowex 50Wx2, Amberlyst 31 and Dowex 50Wx4 and macroreticular resins with low crosslinking degree Amberlyst 70 and Amberlyst 39 show low polymer densities $\left(0.2-0.8 \mathrm{~nm}^{-}\right.$

${ }^{2}$ ) typical of an expanded polymer whereas macroreticular resins with medium and high crosslinking degree CT-482, Amberlyst 36, Amberlyst 16, Amberlyst 35, Amberlyst 15 and Amberlyst 46 present high chains concentration $\left(1.5-2 \mathrm{~nm}^{-2}\right)$ characteristic of a very dense polymer mass. It is to be noted that Dowex $50 \mathrm{Wx} 8$, in spite of being a gel-type resin, shows zones with high polymer density $\left(2 \mathrm{~nm}^{-2}\right)$. That behavior is probably due to its high DVB\%.

\subsection{Apparatus}

Experiments were carried out in a 100-mL-cylindrical high pressure autoclave made of 316 stainless steel (maximum temperature: $232^{\circ} \mathrm{C}$; pressure range: $0-150$ bar). It was equipped with a magnetic drive stirrer and with a $400 \mathrm{~W}$ electrical furnace for heating. Temperature was measured by a thermocouple located inside the reactor and stirring speed was measured by a tachometer. Both operation variables were controlled to $\pm 1^{\circ} \mathrm{C}$ and $\pm 1 \mathrm{rpm}$ respectively by an electronic control unit. An injection system attached to the reactor was used to load the catalyst once the operating conditions were reached. One of the outlets of the reactor was connected directly to a liquid sampling valve, which injected $0.2 \mu \mathrm{L}$ of pressurized liquid into a gas-liquid chromatograph.

\subsection{Analysis}

In order to follow the course of the reaction, the composition of the liquid mixture was analyzed in-line by a 7820A GC System equipped with a TCD detector able to measure the presence of water. The capillary column used was a dimethylpolysiloxane HP-Pona (50 m x $0.200 \mathrm{~mm}$ x 
$1600.50 \mu \mathrm{m})$. Helium was used as the carrier gas $\left(70 \mathrm{~mL} \cdot \mathrm{min}^{-1}\right.$, constant flow $)$. Chromatograph

161 parameters were: volume injection $0.2 \mu \mathrm{L}$; split ratio $100: 1$; injector temperature $150{ }^{\circ} \mathrm{C}$; oven

162 program: $45^{\circ} \mathrm{C}$ for $5.5 \mathrm{~min}, 50^{\circ} \mathrm{C} \cdot \mathrm{min}^{-1}$ up to $180^{\circ} \mathrm{C}$ which was held for $5 \mathrm{~min}$. TCD

163 parameters were: detector temperature $250^{\circ} \mathrm{C}$; reference flow $20 \mathrm{~mL} \cdot \mathrm{min}^{-1}$; makeup flow 4.9

$164 \mathrm{~mL} \cdot \mathrm{min}^{-1}$.

165 A second GC equipped with a MS (Agilent GC/MS 5973) and chemical database software was

166 used to identify all the species.

\subsection{Methodology and calculations}

168

169

170

\subsubsection{Resin screening}

Wet resins (as provided by the supplier) were dried at room temperature during $24 \mathrm{~h}$ prior to undergo mechanical sieving. Resin samples with bead size between $0.40-0.63 \mathrm{~mm}$ were dried at $110^{\circ} \mathrm{C}$, firstly at 1 bar during $2 \mathrm{~h}$ and then at 10 mbar during $15 \mathrm{~h} .1$-butanol was charged in the reactor and heated to $150{ }^{\circ} \mathrm{C}$. The reaction mixture was pressurized to 40 bar by means of $\mathrm{N}_{2}$ in order to assure the liquid phase reaction medium. Stirring speed was set at $500 \mathrm{rpm}$. After reaching the working temperature, $1 \mathrm{~g}$ of dry catalyst was injected by means of pneumatic transport. That moment was considered the starting point of reaction. To follow the variation of concentration of reactants and products with time, liquid samples were taken out hourly and analyzed in-line as mentioned above. Total length of the experiments was $7 \mathrm{~h}$. In all the experiments mass balance was accomplished within $\pm 8 \%$.

An additional series of experiments was performed over Amberlyst 31 and Amberlyst 15 to test their thermal stability and reusability. These resins have one of the lower maximum operation temperatures within the gel-type group and the macroreticular group respectively (Table 1). Each resin was used for three cycles. In the first cycle fresh catalysts were used following the experimental procedure above mentioned. After a $7 \mathrm{~h}$ experiment the reactor was cooled at the room temperature, catalyst was filtered out from the reaction medium, washed with $25 \mathrm{ml}$ of 
methanol, dried at ambient temperature during $24 \mathrm{~h}$ then dried at $110{ }^{\circ} \mathrm{C}$, firstly at 1 bar during 2 $\mathrm{h}$ and then at 10 mbar during $15 \mathrm{~h}$ before being subjected to a new reaction cycle.

187 In each experiment, 1-butanol conversion $\left(\mathrm{X}_{\mathrm{BuOH}}\right)$, selectivity to products $\left(\mathrm{S}_{\mathrm{j}}\right.$, the subscript $\mathrm{j}$ corresponding to each formed product) and DNBE yield ( $\left.\mathrm{Y}_{\mathrm{DNBE}}\right)$ were estimated as follows:

$$
\begin{aligned}
& \mathrm{X}_{\mathrm{BuOH}}=\frac{\text { mole of } 1-\text { bu tanol reacted }}{\text { initial mole of } 1-\text { bu tanol }} \\
& \mathrm{S}_{\mathrm{DNBE}}=\frac{\text { mole of } 1-\text { bu tan ol reacted to form DNBE }}{\text { mole of } 1-\text { bu tan ol reacted }}
\end{aligned}
$$

Selectivity to olefins $\left(\mathrm{S}_{1-\text { butene }}, \mathrm{S}_{(\mathrm{E}) 2 \text {-butene }}\right.$ and $\left.\mathrm{S}_{(\mathrm{Z}) 2 \text {-butene }}\right)$ branched ether 1-(1-methylpropoxy)

butane $\left(\mathrm{S}_{\mathrm{BuOBu}}\right)$ and 2-butanol $\left(\mathrm{S}_{2-\mathrm{BuOH}}\right)$ were defined similarly.

$$
\mathrm{Y}_{\mathrm{DNBE}}=\frac{\text { mole of } 1-\text { bu tan ol reacted to form DNBE }}{\text { initial mole of } 1-\text { bu tan ol }}=\mathrm{X}_{\mathrm{BuOH}} \cdot \mathrm{S}_{\mathrm{DNBE}}
$$

191 In addition, initial reaction rate of DNBE formation ( $\left.\mathrm{r}_{\mathrm{DNBE}}^{0}\right)$ was computed from the function of 192 the experimental curve of DNBE mole ( $\left.\mathrm{n}_{\mathrm{DNBE}}\right)$ vs. time according to:

$$
\mathrm{r}_{\mathrm{DNBE}}^{0}=\frac{1}{\mathrm{~W}_{\text {cat. }}}\left(\frac{\mathrm{dn}_{\mathrm{DNBE}}}{\mathrm{dt}}\right)_{\mathrm{t}=0}
$$

Initial turnover frequency for DNBE formation $\left(\mathrm{TOF}^{0}{ }_{\mathrm{DNBE}}\right)$ was estimated by dividing $\mathrm{r}_{\mathrm{DNBE}}^{0}$ by

194 the acid capacity:

$$
\mathrm{TOF}_{\mathrm{DNBE}}^{0}=\frac{\mathrm{r}_{\mathrm{DNBE}}^{0}}{\text { acid capacity }}
$$

\subsubsection{Presence of byproducts in the feed composition}

The influence of typical 1-butanol impurities on the dehydration of 1-butanol to DNBE was studied. If 1-butanol is produced by the oxo process the main impurity is isobutanol whereas if

198 it is produced by the ABE fermentation process impurities are and ethanol and acetone.

199 Experiments were carried out with different mixtures of 1-butanol : isobutanol (95:5 and 90:10 $w t \%)$ and 1-butanol:ethanol:acetone (95:2.5:2.5 and 90:5:5 wt\%) over the highly selective 
resins Amberlyst 70, Amberlyst 31 and Amberlyst 121. The experimental procedure and reaction conditions were the same as for catalyst testing: $1 \mathrm{~g}$ of dry catalyst, catalyst bead size between $0.400-0.630 \mathrm{~mm}, 150^{\circ} \mathrm{C}, 40 \mathrm{bar}, 500 \mathrm{rpm}$, and $7 \mathrm{~h}$.

\section{Results and discussion}

\subsection{Reaction Network}

206 Dehydration of 1-butanol over the ion exchange resins tested leads to the formation of di-n-

207 butyl ether as main product. Detected byproducts were $\mathrm{C}_{4}$ olefins (1-butene, trans- and cis- 2butene), the branched ether 1-(1-methylpropoxy) butane and, in much smaller amount, 2butanol. Figure 2 shows the evolution of the liquid phase composition over the course of an experiment conducted on Amberlyst 15. Products distribution on all tested resins is similar although it should be pointed out some significant differences: (1) over macroreticular resins with low crosslinking degree (Amberlyst 39 and Amberlyst 70) and gel type resins (Amberlyst 31, Amberlyst 121, Dowex 50x4 and Dowex 50x2) 2-butanol was not detected; (2) after 7 hours reaction time most resins showed higher selectivity to 2-butenes than to 1-butene except for Amberlyst 70, Amberlyst 121 and Dowex 50x2. This fact may be due to the very low total amount of butenes formed on those resins.

Figure 2 .

218 Distribution of products suggests the reaction network of Figure 3. Dehydration of 1-butanol to di-n-butyl ether (DNBE) is the main reaction (R1). Dehydration to olefins is the main side reaction (R2). The fact that at very low olefins concentration the major $\mathrm{C}_{4}$ product was 1-butene whereas when olefins concentration increase 2-butenes are favored, especially trans-2-butene, indicates that 1-butanol dehydrates to 1-butene which in his turn isomerizes to trans-2-butene and cis-2-butene (R3); the trans-isomer being thermodynamically more stable. The resins sites are also active for catalyzing the reverse reactions of (R1) and (R2), ether hydrolysis (R4) and olefin hydration (R5). When olefin hydration takes place, the alcohol that is formed is no longer a primary alcohol. In addition to double bond isomerization, 2-butenes could be formed by hydration of 1-butene to 2- butanol and its subsequent dehydration, giving place to any of the 
three $\mathrm{C}_{4}$ olefins. From the fact 1-(1-methylpropoxy)butane was detected over all the resins despite the nonexistence of 2-butanol on some catalysts, it is inferred that the branched ether could be preferably formed by 1-butanol reaction with a $\mathrm{C}_{4}$ olefin (R6) instead of by the reaction between 1-butanol and 2-butanol. Furthermore, the absence of 2,2'-oxydibutane indicates that intermolecular dehydration of two molecules of 2-butanol is not taking place, probably due to the low concentration of the secondary alcohol in the reaction medium.

Figure 3.

\subsection{1-Butanol conversion, initial reaction rate, selectivity to DNBE and DNBE yield}

Table 3 shows 1-butanol conversion, selectivity to DNBE and byproducts, and yield of DNBE at $7 \mathrm{~h}$ reaction time. Initial reaction rate and turnover frequency of DNBE synthesis are also given. Data has a relative experimental error lower than $\pm 4 \%$ for $\mathrm{X}_{\mathrm{BuOH}}, \pm 1 \%$ for $\mathrm{S}_{\mathrm{DNBE}}, \pm 5 \%$ for $\mathrm{Y}_{\mathrm{DNBE}}$ and $\pm 7 \%$ for $\mathrm{r}_{\mathrm{DNBE}}^{0}$ and $\mathrm{TOF}_{\mathrm{DNBE}}^{0}$. Due to the low concentration of byproducts in the reaction medium, $S_{\text {byproducts }}$ data has in some cases a relative experimental error up to $\pm 20 \%$.

Taking into account that some preliminary long-time experiments $(>72 \mathrm{~h})$ showed that equilibrium conversions are higher than $85 \%$ at the working conditions, it is seen that at the end of experiments the reaction medium is still far from equilibrium. From data of Table 3 it is seen that the most active resins are the oversulfonated resins Amberlyst 36 and Amberlyst 35, whereas the most selective ones are Amberlyst $121>$ Dowex 50Wx2 $>$ Amberlyst $70>$ Amberlyst $46>$ Dowex 50Wx4 $>$ Amberlyst 31. Resins Amberlyst $16>$ Amberlyst $36>$

248 Amberlyst $15>$ Amberlyst 35 show the lowest selectivity to ether. tested resins, $\mathrm{S}_{\mathrm{DNBE}}$ initially decreases and then stabilizes. As a consequence it can be concluded that at these alcohol conversions, the differences observed in $\mathrm{S}_{\mathrm{DNBE}}$ after $7 \mathrm{~h}$ of reaction time are not due to the different reaction extent on each catalyst. On the contrary, they are a consequence of the resins properties, in particular morphology and acid capacity 
Figure 4.

255 Figure 5 show the response surfaces for conversion and selectivity as a function of acid capacity and $\mathrm{V}_{\mathrm{sp}}$, which, together with polymer chain density, is a suitable way of characterizing the polymeric structure of the resins gel type phase. As seen, acid capacity is the parameter which plays the most important role regarding resins activity as it can be inferred from the almost vertical arrangement of colors in the response surface of Figure 5(a). Nevertheless, selectivity to DNBE is influenced by both acid capacity and resin structure as it can be drawn from the diagonal arrangement of colors in the response surface of Figure 5(b).

Figure 5 .

In order to elucidate the influence of acid capacity and polymer morphology on resins behavior, obtained data have been arranged as shown in Figure 6. In this way it is easy to compare on one side, the behavior of resins having the same acid capacity but different polymeric structure and, on the other side, resins with similar values of swollen polymer volume but different acid capacity. Data corresponding to Amberlyst 46 have been omitted in Figure 6 (a), (c) and (d) for the sake of clarity.

Figure 6.

From Figure 6 it can be assumed that a higher acid capacity is essential to a more active catalyst (Figure 6 (a) and (c)) but it also seems to affect the catalyst selectivity to DNBE in a negative way (Figure 6 (b)). Regarding polymer morphology, it plays a decisive role on resin selectivity to DNBE and, although not as significant as acid capacity, it also influences catalytic activity. These facts can be observed by comparing resins with similar acid capacity but different pore structure: (1) Amberlyst 35 and Amberlyst 36 (5.3 meq. $\mathrm{H}^{+} / \mathrm{g}$ ), and (2) Amberlyst 15, Amberlyst 16, Amberlyst 39, Dowex 50Wx8, Amberlyst 31, Dowex 50Wx4, Amberlyst 121 and Dowex $50 \mathrm{Wx} 2$ (around 4.8 meq. $\mathrm{H}^{+} / \mathrm{g}$ ). It can be seen that, as $\mathrm{V}_{\mathrm{sp}}$ rises, $\mathrm{S}_{\mathrm{DNBE}}$ progressively increases until reaching an almost constant value of about $98-99 \%$ with gel-type resins containing $\leq 4 \%$ DVB (Figure 6 (b)). However, in spite of the improvement in catalytic activity observed when 
the $\mathrm{V}_{\mathrm{sp}}$ increases from $0.823 \mathrm{~cm}^{3} / \mathrm{g}$ (Amberlyst 15) to $1.245 \mathrm{~cm}^{3} / \mathrm{g}$ (Amberlyst 16) a further increase in $\mathrm{V}_{\mathrm{sp}}$ leads to a slightly reduction of the resin activity (Figure 6 (a) and (c)).

It is a well-established fact that the alcohols dehydration reaction occurs mainly in the swollen polymer mass [23]. Dehydration reaction to ether follows a $S_{N} 2$ reaction mechanism in which 2 alcohol molecules are involved, whereas dehydration to olefins occurs by a monomolecular reaction of elimination, E1 [30]. As Figure 1 shows, tested resins have zones of different density or polymer chain concentration in the swollen polymer mass ranging from 0.1 to 2.0 $\mathrm{nm} / \mathrm{nm}^{3}$. Very high polymer concentration $\left(2 \mathrm{~nm} / \mathrm{nm}^{3}\right)$ entails a very dense polymer mass, poorly accessible to 1-butanol which leads to a lower catalytic activity. Furthermore, in this dense polymer zone the $S_{N} 2$ reaction is limited to a great extent by steric hindrance and the occurrence of the E1 reaction increases, hence giving place to lower $\mathrm{S}_{\mathrm{DNBE}}$. On the other hand, low polymer concentration corresponding to a greatly expanded polymer enhances selectivity to DNBE. However, too low polymer concentration gives place to a significant distance among its active centers. In this case the probability of disposing the precise orientation of sulfonic groups to form the reaction intermediate lessens and resins activity decreases. Thus, medium values of polymer chain concentration may favor 1-butanol conversion. That could explain the behavior observed in Figure 6 (a) and (c) where, among resins with acid capacity around 4.8 meq. $\mathrm{H}^{+} / \mathrm{g}$, Amberlyst $16\left(\mathrm{~V}_{\mathrm{sp}}=1.245 \mathrm{~cm}^{3} / \mathrm{g}\right.$; polymer density $\left.=0.8-1.5 \mathrm{~nm} / \mathrm{nm}^{3}\right)$ shows a 1-butanol conversion and initial reaction rate higher than those determined on gel-type resins (which have higher $\mathrm{V}_{\mathrm{sp}}$ but polymer densities ranging between $0.2-0.8 \mathrm{~nm} / \mathrm{nm}^{3}$ ). $\mathrm{TOF}^{0}{ }_{\text {DNBE }}$ data (Table 3) confirm that resins with medium $\mathrm{V}_{\mathrm{sp}}$ values shows higher reaction rates per catalytic site. and acid capacity of 4.25 meq. $\mathrm{H}^{+} / \mathrm{g}$ (Table 1 ). This value of acid capacity is not very different from 4.8 meq. $\mathrm{H}^{+} / \mathrm{g}$ and, as seen in Figure 6 (a) and (c), catalytic activity of resin CT-482 is in agreement with data obtained for resins with 4.8 meq. $\mathrm{H}^{+} / \mathrm{g}$. Amberlyst 70 shows smaller 1butanol conversion because of its low acid capacity ( 2.65 meq. $\mathrm{H}^{+} / \mathrm{g}$, Table 2$)$. Furthermore, it can be seen that selectivity to the linear ether over Amberlyst 70, as well as over Amberlyst 46, 
307 is equal to the maximum $\mathrm{S}_{\mathrm{DNBE}}$ value found which corresponds to the gel-type resins Amberlyst

308121 and Dowex 50Wx2. This high selectivity (and therefore, high DNBE content in the final

309 product) is extremely desirable from an environmental standpoint, in addition to the obvious

310 impact on capital requirements and operating costs.

311 As seen in Figure 6 (d) the highest DNBE yield is achieved on Amberlyst-36, nonetheless, gel-

312 type resins and Amberlyst-70 are more selective to the linear ether which makes them more

313 appropriate for industrial use. Among them, Amberlyst-70 can be considered as the most

314 suitable catalyst due to its thermal stability.

315 Finally, Figure 7 shows the combined effect of acid capacity and $V_{\text {sp }}$ on $\mathrm{S}_{\mathrm{DNBE}}$ for all tested

316 resins. As can be seen, $\mathrm{S}_{\mathrm{DNBE}}$ correlates quite well with acid capacity/ $\mathrm{V}_{\mathrm{sp}}$ ratio showing that

317 selectivity to DNBE increases as the number of acid sites per volume unit of swollen polymer

318 (acid density) decreases.

Figure 7.

\subsection{Thermal stability and reusability tests}

Thermal stability and reusability test were conducted over Amberlyst 15 and Amberlyst 31.

These two resins were selected because they have a maximum operating temperature very much lower than $150^{\circ} \mathrm{C}$. Afterwards, BET surface area and acid capacity were measured and compared to those of fresh catalyst. As shown in Table 4 both resins experience some loss of sulfonic acid groups after 3 cycles (fresh resin plus two reused cycles; $21 \mathrm{~h}$ of accumulated working time). BET surface area increases moderately in the case of Amberlyst 15. Despite the small morphological and acid capacity change, performance of the two resins keeps constant throughout the 3 cycles, as it can be seen in Error! No s'ha trobat l'origen de la referència., pointing out that results are not influenced by thermal deactivation and resins can be reused a few cycles. In order to take into account the differences in initial alcohol and catalysts mass

331 (due to small catalysts losses in recovering and cleaning the resin operations), the factor $\mathrm{X}_{1-}$ $\mathrm{BuOH} \cdot \mathrm{n}^{0}{ }_{1-\mathrm{BuOH}} / \mathrm{W}_{\text {cat }}$ is used instead of $\mathrm{X}_{1-\mathrm{BuOH}}$. The differences observed for $\mathrm{r}^{0}{ }_{\mathrm{DNBE}}$ between Error! 
and Amberlyst 15 are due to the fact that in this series of experiments the injector was not used. Thus, catalyst was charged into the reactor and then heated to $150^{\circ} \mathrm{C}$; the moment in which this temperature was reached was considered as the beginning of the experiment (zero time). It is to be noted that despite this change of methodology the results are quite similar. It is concluded from these reusing experiments that data reported in Table 3 are reliable. It can be accepted that accessible zone of resins increases on losing active centers, and this effects are mutually balanced. However, as resins show a clear trend to morphological instability it is suitable to use resins with high thermal stability such us Amberlyst 70 for industrial application.

Table 4.

Figure 8 .

\subsection{Influence of typical 1-butanol impurities}

\subsubsection{Influence of 2-methyl-1-propanol (isobutanol)}

Figure 9 shows the influence of isobutanol presence on the dehydration of 1-butanol to DNBE at $7 \mathrm{~h}$ reaction. As seen, the trend is very similar over the three tested resins: the selectivity to DNBE decreases on increasing the initial concentration of the branched alcohol mainly due to the increment in 1-(1-methylpropoxy)butane formation. It is quoted in the open literature that alcohols can undergo alkyl group transpositions [31]. In primary alcohols, after protonating to form the alkyloxonium ion, steric hindrance interferes in the direct displacement of the leaving group (water) by the nucleophile; instead water leaves at the same time as the alkyl group shifts from the adjacent carbon to skip the formation of the unstable primary carbocation. This mechanism is known as "Concerted Alkyl Shift" (Figure 10). Thus, the increasing amounts of 1-(1-methylpropoxy)butane detected when isobutanol is initially in the reaction medium is explained by the reaction of 1-butanol with the secondary carbocation which results from isobutanol dehydration and alkyl group shift. The rearrangement of products during isobutanol dehydration in the presence of strong Brönsted acid sites is also reported by Kotsarenko and Malysheva [32]. 1-(2methylpropoxy) butane was also detected in the reaction medium over the 

ether is formed when a molecule of isobutanol reacts with a molecule of 1-butanol (R7).

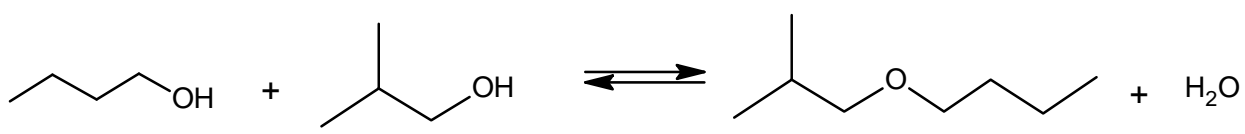

362 No significant change was observed on olefins concentration despite the addition of isobutanol in the reaction medium. Olefin 2-methyl propene (isobutylene) consequence of isobutanol intermolecular dehydration was not detected at these reaction conditions, probably due to the low isobutanol initial concentration and conversion extent. However, even though the amount of olefins, which are the most problematic byproduct, hardly changes by the isobutanol presence in the initial reaction mixture, it should be avoided as it increases the formation of branched ethers which present worse performance properties than the linear ether [8].

\subsubsection{Influence of ethanol and acetone}

372 Two new byproducts were mainly detected when ethanol and acetone were added into the feed composition: the major one was ethyl butyl ether (EBE) which is formed by the dehydration reaction between a molecule of 1-butanol and a molecule of ethanol (R8); the another one, detected only in very low amounts, was di-ethyl ether (DEE) which is the product of ethanol intermolecular dehydration (R9).

As it can be seen in Figure 11 selectivity to DNBE decreased whereas EBE formation increased when the initial amount of ethanol rises even at high 1-butanol:ethanol initial ratios. Similarly, in the dehydration reaction of 1-octanol/ethanol mixtures at $150^{\circ} \mathrm{C}$ over acidic ion exchangers, ethers with lower molecular weight are preferentially formed [33]. At present experimental conditions the small amount of DEE detected is due to the high initial 1-butanol:ethanol ratios.

382 DEE must be avoided as it cannot be blended directly into commercial diesel fuels.

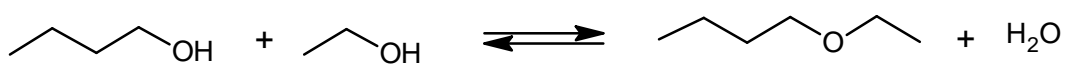




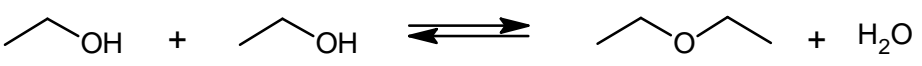

383

384

Regarding acetone reactivity, its condensation/dehydration forming mesityl oxide (MSO) and water over Amberlyst 16 in the temperature range $100-120^{\circ} \mathrm{C}$ has been quoted [34]. Still, under the current experimental conditions acetone hardly react and only very low amounts of 2propanol were detected (always less than $0.04 \%$ chromatographic area/g of catalyst). 2-Propanol could be the product of the acetone hydrogenation catalyzed by component of stainless steel tubing's and reactor walls such as nickel or iron. The amount of olefins (1-butene, trans-2butene and cis-2-butene) and the branched ether 1-(1-methylpropoxy)butane did not experiment significant changes despite ethanol/acetone addition. Comparing the catalytic behavior of the three resins it can be concluded that, as found when isobutanol was added, the presence of ethanol and acetone in the reaction medium does not change significantly the general trend observed when 1-butanol is free of impurities.

Figure 11.

\section{Conclusions}

Sulfonic S/DVB resins are shown to be suitable catalysts for the dehydration reaction of 1butanol to di-n-butyl ether in the liquid phase. Activity (reaction rate and conversion of 1butanol) is enhanced with higher acid capacity (oversulfonated resins) and with medium values of swollen polymer volume $\left(0.823-1.245 \mathrm{~cm}^{3} / \mathrm{g}\right)$. Very high polymer concentration entails a very dense polymer mass, poorly accessible to 1-butanol. On the contrary, very low polymer concentration corresponds to a greatly expanded polymer which gives place to a high distance among its active centers. As a result, the probability of disposing the precise conformation of sulfonic groups to form the reaction intermediate lessens and 1-butanol conversion decreases. Amberlyst 36 (oversulfonated, medium values of \%DVB) has proved to be the most active catalysts tested. However, gel-type resins (which have a flexible morphology and are able to greatly swell in the reaction medium) and the resins Amberlyst-70 and Amberlyst-46 are more selective to DNBE; the resin Amberlyst 121 being the most selective. DNBE formation follows 
a $\mathrm{S}_{\mathrm{N}} 2$ reaction mechanism in which 2 molecules of 1-butanol are involved, whereas dehydration to butenes occurs through a monomolecular reaction of elimination, E1. As a consequence, in highly expanded polymers the $\mathrm{S}_{\mathrm{N}} 2$ reaction is not limited by steric hindrance yielding higher selectivity to the linear ether. In addition, a clear relationship between selectivity and $\mathrm{H}^{+} / \mathrm{V}_{\mathrm{sp}}$ ratio has been observed; the resins with lowest $\mathrm{H}^{+} / \mathrm{V}_{\mathrm{sp}}$ being the most selective.

413 The presence of 2-methyl-1-propanol in the initial reactant mixture enhances the formation of 414 branched ethers, which have worse properties as diesel components than linear ones. However no significant changes were observed in the concentration of olefins which are the most troublesome byproducts regarding the sought properties for fuel additives. On the other hand,

417 the presence of ethanol and acetone leads to the formation of ethyl butyl ether and di-ethyl ether

418 but in a much lesser extent. Di-ethyl ether must be avoided as it cannot be blended directly into 419 commercial diesel fuels.

\section{Acknowledgment}

421 Financial support was provided by the Science and Education Ministry of Spain (project: CTQ2010-16047). The authors thank Rohm and Haas France and Purolite for providing Amberlyst and CT ion-exchange resins, respectively. We also thank Dr. Karel Jerabek of Institute of Chemical process Fundamentals (Prague, Czech Republic) for the morphological analyses made by the ISEC method

\section{Nomenclature}

$\begin{array}{ll}\text { AAS } & \text { amorphous aluminosilicate } \\ \text { ABE } & \text { acetone-butanol-ethanol } \\ \text { BET } & \text { Brunauer-Emmet-Teller } \\ \text { CFPP } & \text { cold filter plugging point } \\ \text { CP } & \text { cloud point } \\ \mathrm{d}_{\text {pore }} & \text { mean pore diameter }(\mathrm{nm}) \\ \mathrm{EBE} & \text { ethyl butyl ether } \\ \mathrm{DEE} & \text { di-ethyl ether } \\ \mathrm{ISEC} & \text { inverse steric exclusion chromatography } \\ \mathrm{DNBE} & \text { di-n-butyl ether } \\ \mathrm{MSO} & \text { mesityl oxide } \\ \mathrm{n}_{\mathrm{DNBE}} & \text { mole number of di-n-butyl ether }(\text { mol }) \\ \mathrm{RVP} & \text { Reid vapor pressure } \\ \mathrm{r}_{\mathrm{DNBE}}^{0} & \text { initial reaction rate }(\mathrm{mol} / \mathrm{h} \cdot \mathrm{kg} \text { of dry catalyst) }\end{array}$




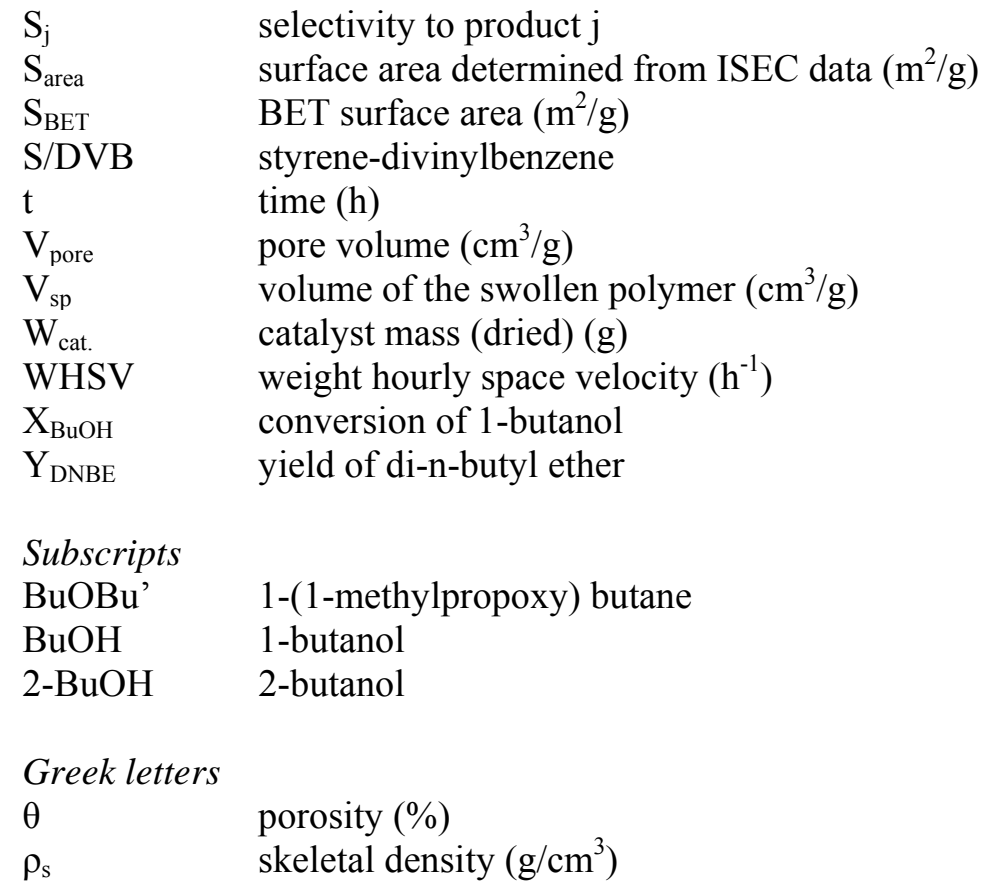

\section{References}

[1] L.S. Ott, B. L. Smith, T. J. Bruno, Energy Fuels 22 (2008) 2518-2516.

[2] M.N. Nabi, D. Kannan, J.E. Hustad, M.M. Rahman, in: Role of Oxygenated Fuel to Reduce

Diesel Emissions: A Review. International Conference on Mechanical Engineering, Dhaka, Bangladesh, 2009.

[3] A. Golubkov, Motor Fuels for diesel engines. Patent WO2001018154 A1 (2001).

[4] T.J.A. Alander, A.P. Leskinen, T.M. Raunemaa, L. Rantanen, Environ. Sci. Technol. 38 (2004) 2707-2714.

[5] A. Arteconi, A. Mazzarini, G. Di Nicola, Water, Air, Soil, Pollut. 221 (2011) 405-423.

[6] I. Sezer, A. Bilgin, Energy Fuels. 22 (2008) 1341-1348.

[7] R.L. McCormick, J.D. Ross, M.S. Graboski, Environ. Sci. Technol. 31 (4) (1997) 11441150.

[8] G. C. Pecci, M.G. Clerici, F. Giavazzi, F. Ancillotti, M. Marchionna, R. Patrini, IX International Symposium on Alcohol Fuels, 1 (1991) 321-326. 
[9] M. Marchionna, R. Patrini, F. Giavazzi, G. C. Pecci, Symposium on Removal of Aromatics, Sulfur and Alkenes from Gasoline and Diesel, $212^{\text {th }}$ National Meeting, ACS, (1996) 585-589.

[10] L. S. Starkey, Introduction to Strategies for Organic Synthesis, Wiley, Hoboken, NJ, 2012. Chapter 3.3

[11] R.A. Sheldon, H. van Bekkum, Fine Chemical through Heterogeneous Catalysis, WileyVCH, Weinheim (Germany), 2001, Chapter 6.5.

[12] Chemsystems Perp Program, Oxo Alcohols PERP 06/07-08. www.chemsystem.com $(07 / 2013)$

[13] T. Tsuchida, S. Sakuma, T. Takeguchi, W. Ueda, Ind. Eng. Chem. Res. 45 (2006) 86348642.

[14] R. Cascone, Chem. Eng. Progress 104(8) (2008) S4-S9

[15] http://www.biofuelstp.eu/butanol.html European Biofuels Technology Platform (07/2013)

[16] Anonymous, Chem. Eng. Progress 103 (2007) 14.

[17] R. J. J. Nel, A. de Klerk, Ind. Eng. Chem. Res. 48 (2009) 5230-5238.

[18] M. A. Makarova, E. A. Paukshtis, J. M. Thomas, C. Williams, K. I. Zamaraev, J. Catal. 149 (1994) 36-51.

[19] F.M. Bautista, B. Delmon, Appl. Catal. A: General. 130 (1995) 47-65.

[20] P. Brandão, A. Philippou, J. Rocha, M. W. Anderson, Catal. Letters 80 (3-4) (2002) 99-102

[21] J. H. Choi, J. K. Kim, D. R. Park, S. Park, J. Yi, I. K. Song, Catal. Commun. 14 (2011) 4851.

[22] J. K. Kim, J. H. Choi, J. H. Song, J. Yi, I. K. Song, Catal. Commun. 27 (2012) 5-8

[23] J. Tejero, F. Cunill, M. Iborra, J.F. Izquierdo, C. Fité, J. Mol. Catal. A: Chem. 182 (2002) $541-554$ 
[24] R. Bringué, M. Iborra, J. Tejero, J.F. Izquierdo, F. Cunill, C. Fité, V.F. Cruz, J. Catal. 244 (2006) 33-42.

[25] E. Medina, R. Bringué, J. Tejero, M. Iborra, C. Fite, Appl. Catal. A: General. 374 (2010) 41-47.

[26] C. Casas, R. Bringué, E. Ramírez, M. Iborra, J. Tejero, Appl. Catal. A: General. 396 (2011) $129-139$.

[27] K. Jerabek, L. Hantova, Z. Prokop, 12th International Congress on Catalysis, Granada (Spain), 2000.

[28] S. Fisher, R. Kunnin, Anal. Chem. 27 (1955) 1191-1194.

[29] A.G. Ogston, Trans. Faraday Soc. 54 (1958) 1754-1757.

[30] G.A. Olah, T. Shamma, G.K. Surya Prakash, Catal. Lett. 46 (1997) 1-4.

[31] K.P.C. Vollhardt, N.E. Schore, Química Orgánica, 2nd Edition, Ed. Omega, Barcelona (Spain), 2000, Chapter 9.3.

[32] S. Kotsarenko, L.V. Malysheva, Kinet. Katal. 24 (1983) 877-882.

[33] J. Guilera, R. Bringué, E. Ramirez, M. Iborra, J. Tejero, Ind.Eng.Chem.Res. 51 (2012) $16525-16530$.

[34] E.du Toit, R.Schwarzer,W. Nicol, Chem. Eng. Sci. 59 (2004) 5545-5550. 
Table 1. Properties of tested catalysts

\begin{tabular}{|c|c|c|c|c|c|c|}
\hline Catalyst & $\begin{array}{l}\text { Short } \\
\text { name }\end{array}$ & Structure $^{\mathrm{a}}$ & $\mathrm{DVB} \%$ & $\begin{array}{l}\text { Sulfonation } \\
\text { Type }^{b}\end{array}$ & $\begin{array}{c}\text { Acidity }^{\mathrm{c}} \\
\left.\text { (meq. } \mathrm{H}^{+} / \mathrm{g}\right)\end{array}$ & $\begin{array}{l}\mathrm{T}_{\max }{ }^{\mathrm{d}} \\
\left({ }^{\circ} \mathrm{C}\right)\end{array}$ \\
\hline Amberlyst- 15 & A-15 & $\mathrm{M}$ & 20 & $\mathrm{M}$ & 4.81 & 120 \\
\hline Amberlyst-35 & A-35 & M & 20 & $\mathrm{O}$ & 5.32 & 150 \\
\hline Amberlyst-16 & A-16 & M & 12 & M & 4.8 & 130 \\
\hline Amberlyst-36 & A-36 & M & 12 & $\mathrm{O}$ & 5.4 & 150 \\
\hline CT-482 & CT-482 & M & Medium & M & 4.25 & 190 \\
\hline Amberlyst-70 & A-70 & M & 8 & M & 2.65 & 190 \\
\hline Amberlyst-39 & A-39 & M & 8 & M & 5.0 & 130 \\
\hline Dowex 50Wx8 & DOW-8 & $\mathrm{G}$ & 8 & M & 4.83 & 150 \\
\hline Amberlyst-31 & A-31 & $\mathrm{G}$ & 4 & M & 4.8 & 130 \\
\hline Dowex $50 \mathrm{Wx} 4$ & DOW-4 & $\mathrm{G}$ & 4 & M & 4.95 & 150 \\
\hline Amberlyst-121 & A-121 & $\mathrm{G}$ & 2 & M & 4.8 & 130 \\
\hline Dowex 50Wx2 & DOW-2 & G & 2 & M & 4.83 & 150 \\
\hline Amberlyst-46 & A-46 & $\mathrm{M}$ & High & $\mathrm{S}$ & 0.87 & 120 \\
\hline
\end{tabular}

${ }^{a}$ Macroreticular structure $(\mathrm{M})$ or gel-type structure $(\mathrm{G})$

${ }^{\mathrm{b}}$ Monosulfonated (M), oversulfonated (O) or sulfonated only at the polymer surface (S)

${ }^{\mathrm{c}}$ Titration against standard base following the procedure described by Fisher and Kunin [28].

${ }^{\mathrm{d}}$ Information supplied by manufacturer

Table 2. Morphology of tested catalyst in dry state and swollen in water

\begin{tabular}{|c|c|c|c|c|c|c|c|c|c|}
\hline \multirow{3}{*}{ Catalyst } & \multirow{3}{*}{$\begin{array}{c}\rho_{\mathrm{s}}^{\mathrm{a}} \\
\left(\mathrm{g} / \mathrm{cm}^{3}\right)\end{array}$} & \multicolumn{3}{|c|}{ Dry state } & \multicolumn{5}{|c|}{ Swollen in water (ISEC method) } \\
\hline & & \multirow{2}{*}{$\begin{array}{c}\mathrm{S}_{\mathrm{BET}}^{\mathrm{b}} \\
\left(\mathrm{m}^{2} / \mathrm{g}\right)\end{array}$} & \multirow{2}{*}{$\begin{array}{c}\mathrm{V}_{\text {pore }}{ }^{\mathrm{c}} \\
\left(\mathrm{cm}^{3} / \mathrm{g}\right)\end{array}$} & \multirow{2}{*}{$\begin{array}{l}d_{\text {pore }}{ }^{d} \\
(\mathrm{~nm})\end{array}$} & \multicolumn{3}{|c|}{ "True Pores" } & \multicolumn{2}{|c|}{ Gel polymer } \\
\hline & & & & & $\begin{array}{l}\mathrm{S}_{\mathrm{ISEC}} \mathrm{e}^{2}\left(\mathrm{~m}^{2} / \mathrm{g}\right)\end{array}$ & $\begin{array}{c}\mathrm{V}_{\text {ISEC }}{ }^{\mathrm{f}} \\
\left(\mathrm{cm}^{3} / \mathrm{g}\right)\end{array}$ & $\begin{array}{l}\mathrm{d}_{\text {pore }}{ }^{\mathrm{d}} \\
(\mathrm{nm})\end{array}$ & $\begin{array}{c}\mathrm{V}_{\mathrm{sp}} \\
\left(\mathrm{cm}^{3} / \mathrm{g}\right)\end{array}$ & $\begin{array}{c}\theta_{\text {Total }}{ }^{9} \\
(\%)\end{array}$ \\
\hline A-15 & 1.416 & 42.01 & 0.328 & 31.8 & 157 & 0.632 & 16.1 & 0.823 & 51.5 \\
\hline A-35 & 1.542 & 28.90 & 0.210 & 23.6 & 166 & 0.623 & 15.0 & 0.736 & 52.3 \\
\hline A-16 & 1.401 & 1.69 & 0.013 & 29.7 & 149 & 0.384 & 10.3 & 1.245 & 56.2 \\
\hline A-36 & 1.567 & 21.00 & 0.143 & 27.0 & 147 & 0.333 & 9.1 & 0.999 & 52.1 \\
\hline CT-482 & 1.538 & 8.7 & 0.06 & 26.8 & 214 & 1.051 & 18.5 & 1.081 & 69.5 \\
\hline A-70 & 1.520 & 0.02 & & & 176 & 0.355 & 8.1 & 1.15 & 56.3 \\
\hline A-39 & 1.417 & 0.09 & $2.9 \times 10^{-4}$ & 17.6 & 181 & 0.36 & 7.9 & 1.451 & 61.0 \\
\hline DOW8 & 1.430 & 0.23 & & & & & & 1.627 & 57.0 \\
\hline A-31 & 1.426 & 0.10 & $3.3 \times 10^{-4}$ & 15.3 & & & & 1.933 & 63.7 \\
\hline DOW4 & 1.426 & 0.01 & & & & & & 1.92 & 63.5 \\
\hline A-121 & 1.428 & 0.02 & $3.5 \times 10^{-4}$ & 32.9 & & & & 3.263 & 78.5 \\
\hline DOW2 & 1.426 & 1.32 & & & & & & 2.655 & 73.6 \\
\hline A- 46 & 1.137 & 57.4 & 0.263 & 19.2 & 186 & 0.48 & 10.3 & 0.16 & 0.0 \\
\hline
\end{tabular}

\footnotetext{
a Skeletal density measured by Helium displacement

${ }^{\mathrm{b}}$ BET (Brunauer-Emmet-Teller) surface area

${ }^{c}$ Pore volume determined by adsorption-desorption of $\mathrm{N}_{2}$ at $77 \mathrm{~K}$

${ }^{\mathrm{d}}$ Mean pore diameter. Assuming pore cylindrical model: $4 V_{\text {pore }} / S_{\text {BET }}$ or $4 V_{\text {ISEC }} / S_{\text {ISEC }}$

${ }^{\mathrm{e}}$ Surface area determined from ISEC data

${ }^{\mathrm{f}}$ Pore volume determined from ISEC data

${ }^{\mathrm{g}}$ Porosity estimated as $100 \mathrm{~V}_{\mathrm{g}} /\left(\mathrm{V}_{\text {pore }}+\left(1 / \rho_{\mathrm{s}}\right)\right)$ in dry state and as $100\left(\mathrm{~V}_{\mathrm{ISEC}}+\mathrm{V}_{\mathrm{sp}}-\left(1 / \rho_{\mathrm{s}}\right)\right) /\left(\mathrm{V}_{\text {ISEC }}+\mathrm{V}_{\mathrm{sp}}\right)$ in swollen state
} 
Table 3. Conversion of 1-butanol, selectivity to DNBE and byproducts, yield to DNBE at $7 \mathrm{~h}$ reaction, initial reaction rate and turnover frequency for DNBE formation $(1 \mathrm{~g}$ catalyst, catalyst bead size $=0.400-0.630 \mathrm{~mm}, \mathrm{~T}=150^{\circ} \mathrm{C}, \mathrm{P}=40$ bar).

\begin{tabular}{|c|c|c|c|c|c|c|c|c|c|c|}
\hline Catalyst & $\begin{array}{c}\mathrm{X}_{\mathrm{BuOH}} \\
\%\end{array}$ & $\begin{array}{c}\mathrm{S}_{\mathrm{DNBE}} \\
\%\end{array}$ & $\begin{array}{c}\mathrm{S}_{1-\text { Butene }} \\
\%\end{array}$ & $\begin{array}{c}\mathrm{S}_{(\mathrm{E}) 2-\text { Butene }} \\
\%\end{array}$ & $\begin{array}{c}\mathrm{S}_{(\mathrm{Z}) 2-\text { Butene }} \\
\%\end{array}$ & $\begin{array}{c}\mathrm{S}_{2-\mathrm{BuOH}} \\
\%\end{array}$ & $\begin{array}{c}\mathrm{S}_{\mathrm{BuOBu}} \\
\%\end{array}$ & $\begin{array}{c}\mathrm{Y}_{\mathrm{DNBE}} \\
\%\end{array}$ & $\begin{array}{c}\mathrm{r}_{\mathrm{DNBE}}^{0} \\
\mathrm{~mol} / \mathrm{h} \mathrm{kg}\end{array}$ & $\begin{array}{l}\mathrm{TOF}_{\mathrm{DNBE}}^{0} \\
\mathrm{~mol} / \mathrm{h} \text { eq H}\end{array}$ \\
\hline A-15 & 18.4 & 81.7 & 1.27 & 4.89 & 2.74 & 0.890 & 8.56 & 15.0 & 15.6 & 3.25 \\
\hline A-35 & 22.2 & 74.8 & 1.38 & 6.35 & 3.46 & 1.33 & 12.7 & 16.6 & 22.9 & 4.30 \\
\hline A-16 & 19.9 & 92.9 & 0.753 & 1.65 & 0.994 & 0.343 & 3.33 & 18.5 & 17.2 & 3.59 \\
\hline A-36 & 23.2 & 86.4 & 0.934 & 3.30 & 1.87 & 0.725 & 6.76 & 20.1 & 28.1 & 5.20 \\
\hline CT-482 & 19.3 & 95.8 & 0.707 & 0.917 & 0.634 & 0.215 & 1.74 & 18.4 & 15.8 & 3.72 \\
\hline A-70 & 14.1 & 98.7 & 0.479 & 0.120 & 0.096 & trace & 0.595 & 14.0 & 10.3 & 3.90 \\
\hline A-39 & 19.4 & 97.1 & 0.613 & 0.559 & 0.407 & 0.0798 & 1.21 & 18.8 & 16.1 & 3.21 \\
\hline Dow-8 & 19.4 & 96.2 & 0.644 & 0.795 & 0.551 & 0.191 & 1.60 & 18.7 & 15.8 & 3.26 \\
\hline A-31 & 18.9 & 98.1 & 0.513 & 0.321 & 0.235 & 0.0431 & 0.759 & 18.5 & 14.5 & 3.02 \\
\hline Dow-4 & 18.6 & 98.4 & 0.481 & 0.265 & 0.215 & trace & 0.679 & 18.3 & 13.8 & 2.79 \\
\hline A-121 & 17.6 & 99.1 & 0.423 & 0.0118 & trace & 0 & 0.440 & 17.5 & 13.2 & 2.75 \\
\hline Dow-2 & 18.4 & 98.9 & 0.379 & 0.151 & 0.136 & 0 & 0.458 & 18.2 & 12.7 & 2.64 \\
\hline A- -46 & 3.25 & 98.7 & trace & trace & trace & 0 & 1.32 & 3.21 & 1.64 & 1.88 \\
\hline
\end{tabular}

Table 4. Acid capacity and BET surface area of fresh and reused catalysts after 3 reaction cycles $\left(7 \mathrm{~h}, 150^{\circ} \mathrm{C}, 40\right.$ bar $)$

\begin{tabular}{|c|c|c|c|c|c|}
\hline \multirow{2}{*}{ Catalyst } & \multirow{2}{*}{\multicolumn{3}{|c|}{ Acid site $\operatorname{loss}^{\mathrm{a}}(\%)$}} & \multicolumn{2}{|c|}{$\mathrm{S}_{\mathrm{BET}}^{\mathrm{b}}\left(\mathrm{m}^{2} / \mathrm{g}\right)$} \\
\hline & & & & Fresh & Reused \\
\hline Amberlyst 15 & 11.6 & \pm & 3.3 & 42.01 & 43.7 \\
\hline Amberlyst 31 & 8.6 & \pm & 1.9 & 0.10 & 0.10 \\
\hline
\end{tabular}




\section{Figure Captions}

Figure 1. ISEC pattern in water for used resins

Figure 2. Evolution of reaction medium composition with time (1g of Amberlyst-15, catalyst bead size $\left.=0.400-0.630 \mathrm{~mm}, \mathrm{~T}=150^{\circ} \mathrm{C}, \mathrm{P}=40 \mathrm{bar}, 500 \mathrm{rpm}\right):(\boldsymbol{\Delta})$ 1-butanol; $(\bullet)$ water; $(\boldsymbol{\bullet})$

DNBE; $(\star)$ 1-butene; $(\star)$ trans-2-butene; ( $)$ cis-2-butene; $(\boldsymbol{\Xi})$ 1-(1-methylpropoxy)butane; $(\star)$ 2-butanol.

Figure 3. Scheme of reaction network.

Figure 4. $\mathrm{S}_{\mathrm{DNBE}}$ as a function of 1-butanol conversion ( $1 \mathrm{~g}$ catalyst, catalyst bead size $=0.400-$

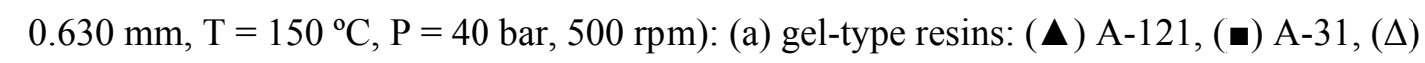

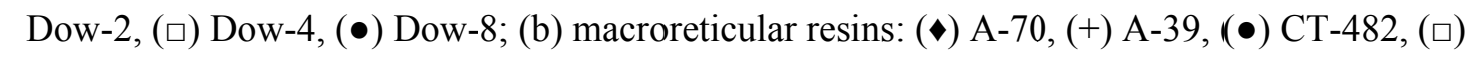
A-16, ( $\Delta$ ) A-15, () A-36, ( $\mathbf{\Delta})$ A-35.

Figure 5. Response surfaces for: (a) 1-butanol conversion; (b) selectivity to DNBE as a function of $\mathrm{V}_{\mathrm{sp}}$ and Acid Capacity. $\mathrm{t}=7 \mathrm{~h}, 1 \mathrm{~g}$ catalyst, catalyst bead size $=0.400-0.630 \mathrm{~mm}, \mathrm{~T}=150$ ${ }^{\circ} \mathrm{C}, \mathrm{P}=40$ bar, $500 \mathrm{rpm}$.

Figure 6. Influence of $\mathrm{V}_{\mathrm{sp}}$ on: (a)1-BuOH conversion; (b) selectivity to di-n-butyl ether; (c) initial reaction rate for DNBE synthesis; (d) DNBE yield. $\mathrm{t}=7 \mathrm{~h}, 1 \mathrm{~g}$ catalyst, catalyst bead size $=0.400-0.630 \mathrm{~mm}, \mathrm{~T}=150{ }^{\circ} \mathrm{C}, \mathrm{P}=40 \mathrm{bar}, 500 \mathrm{rpm}$. ( $\left(\right.$ ) resins with 4.8 meq. $\mathrm{H}^{+} / \mathrm{g}$; ( $)$ resins with 5.3 meq. $\mathrm{H}^{+} / \mathrm{g}$; ( $\left.\mathbf{\square}\right)$ resins with other values of acid capacity.

Figure 7. Selectivity to di-n-butyl ether at $\mathrm{t}=7 \mathrm{~h}$ ( $1 \mathrm{~g}$ catalyst, catalyst bead size $=0.400$ $\left.0.630 \mathrm{~mm}, \mathrm{~T}=150{ }^{\circ} \mathrm{C}, \mathrm{P}=40 \mathrm{bar}, 500 \mathrm{rpm}\right)$ as a function of $\mathrm{H}^{+} / \mathrm{V}_{\mathrm{sp}}$ : (०) resins with 4.8 meq. $\mathrm{H}^{+} / \mathrm{g},(\bullet)$ resins with 5.3 meq. $\mathrm{H}^{+} / \mathrm{g},(\boldsymbol{\bullet})$ resins with other values of acid capacity.

Figure 8. Conversion of 1-butanol $\left(\mathrm{X}_{\mathrm{BUOH}} \cdot \mathrm{n}^{0}{ }_{\mathrm{BuOH}} / \mathrm{W}_{\text {cata }}\right)$ and selectivity to DNBE $\left(\mathrm{S}_{\mathrm{DNBE}}\right)$ at $7 \mathrm{~h}$ reaction and initial reaction rate for DNBE formation $(1 \mathrm{~g}$ catalyst, catalyst bead size $=0.400-$ $0.630 \mathrm{~mm}, \mathrm{~T}=150^{\circ} \mathrm{C}, \mathrm{P}=40$ bar). ( ) Amberlyst 15; ( ) Imberlyst 31 . 
28 Figure 9. Influence of 2-methyl propanol on the dehydration of 1-butanol to DNBE at $7 \mathrm{~h}$

29 reaction. $\mathrm{T}=150^{\circ} \mathrm{C}, \mathrm{P}=40 \mathrm{bar}, 500 \mathrm{rpm}, 1 \mathrm{~g}$ catalyst, catalyst bead size $=0.400-0.630 \mathrm{~mm}:($ $\square)$ DNBE; (m) Olefins; ( $\square$ ) 1-(1-methylpropoxy) butane; ( ) 1-(2-methylpropoxy) butane. Figure 10. Mechanism of Concerted Alkyl Shift.

33 Figure 11. Influence of ethanol and acetone on the dehydration of 1-butanol to DNBE at $7 \mathrm{~h}$

34 reaction. $\mathrm{T}=150^{\circ} \mathrm{C}, \mathrm{P}=40 \mathrm{bar}, 500 \mathrm{rpm}, 1 \mathrm{~g}$ catalyst, catalyst bead size $=0.400-0.630 \mathrm{~mm}:($

$35 \square)$ DNBE; (m) Olefins; ( $\square)$ 1-(1-methylpropoxy) butane; (圆) Ethyl butyl ether; (匹) Diethyl 36 ether. 
34 Table 1. Properties of tested catalysts.

35 Table 2. Morphology of tested catalyst in dry state and swollen in water.

36 Table 3. Conversion of 1-butanol, selectivity to DNBE and side products, yield to DNBE at $7 \mathrm{~h}$

37 reaction, initial reaction rate and turnover frecuency for DNBE formation (1 g catalyst, catalyst

38 bead size $=0.400-0.630 \mathrm{~mm}, \mathrm{~T}=150^{\circ} \mathrm{C}, \mathrm{P}=40$ bar).

39 Table 4. Acid capacity and BET surface area of fresh and reused catalysts after 3 reaction

40 cycles. $\left(7 \mathrm{~h}, 150^{\circ} \mathrm{C}, 40\right.$ bar $)$. 